\title{
Identifying Chagas disease vectors using elliptic Fourier descriptors of body contour: a case for the cryptic dimidiata complex
}

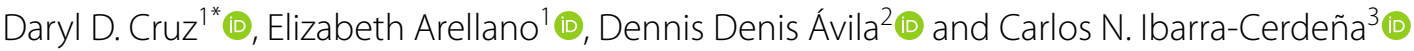

\begin{abstract}
Background: Triatoma dimidiata (Reduviidae: Triatominae) is an important vector of Chagas disease in various countries in the Americas. Phylogenetic studies have defined three lineages in Mexico and part of Central America. While there is a marked genetic differentiation, methods for identifying them using morphometric analyses with landmarks have not yet been fully resolutive. Elliptical Fourier descriptors (EFDs), which mathematically describe the shape of any closed two-dimensional contours, could be a potentially useful alternative method. Our objective was to validate the use of EFDs for the identification of three lineages of this species complex.

Method: A total of 84 dorsal view images of individuals of the three lineages were used. Body contours were described with EFDs using between 5 and 30 harmonics. The number of obtained coefficients was reduced by a principal components analysis and the first axis scores were used as shape variables. A linear discriminant function analysis and an ordination plot of the discriminant analysis were performed using the shape variables. A confusion matrix of the ordination plot of the discriminant analysis was obtained to estimate the classification errors, the first five PC scores were statistically compared, and a neural network were then performed using the shape variables.

Results: The first principal component explained $50 \%$ of the variability, regardless the number of harmonics used. The results of discriminant analysis get improved by increasing the number of harmonics and components considered. With 25 harmonics and 30 components, the identification of haplogroups was achieved with an overall efficiency greater than 97\%. The ordering diagram showed the correct discrimination of haplogroups, with only one error of discrimination corroborated by the confusion matrix. When comparing the first five PC scores, significant differences were found among at least two haplogroups. The 30 multilayer perceptron neural networks were also efficient in identification, reaching $91 \%$ efficiency with the validation data.
\end{abstract}

Conclusions: The use of EFD is a simple and useful method for the identification of the main lineages of Triatoma dimidiata, with high values of correct identification.

Keywords: Triatomine, Identification, Morphometric analysis, Contours, Fourier

*Correspondence: daryldavidcf@gmail.com

${ }^{1}$ Centro de Investigación en Biodiversidad y Conservación (CIByC), UAEM, Cuernavaca, Morelos, México

Full list of author information is available at the end of the article

\begin{abstract}
Background
Cryptic species are one of the great challenges for systematic biologists since, in many cases, speciation is not accompanied by distinctive morphological characters and allopatric distributions that facilitate the identification of different entities at the species level $[1,2]$. For that reason, the actual number of biological species is likely to be greater than the current nominal species count,
\end{abstract}

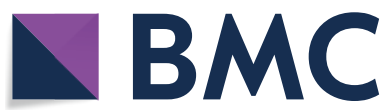

(c) The Author(s) 2020. This article is licensed under a Creative Commons Attribution 4.0 International License, which permits use, sharing, adaptation, distribution and reproduction in any medium or format, as long as you give appropriate credit to the original author(s) and the source, provide a link to the Creative Commons licence, and indicate if changes were made. The images or other third party material in this article are included in the article's Creative Commons licence, unless indicated otherwise in a credit line to the material. If material is not included in the article's Creative Commons licence and your intended use is not permitted by statutory regulation or exceeds the permitted use, you will need to obtain permission directly from the copyright holder. To view a copy of this licence, visit http://creativeco mmons.org/licenses/by/4.0/. The Creative Commons Public Domain Dedication waiver (http://creativecommons.org/publicdomain/ zero/1.0/) applies to the data made available in this article, unless otherwise stated in a credit line to the data. 
most of which are delineated by purely morphological characteristics.

Research focused on cryptic species has increased over the last two decades mainly by the availability of DNA sequences [2]. The use of the term has grown and refers to two or more distinct species that are erroneously classified (hidden) under a single taxonomic entity, but through other evidence, mainly genetic, it can be proved that they have followed different evolutionary paths [3]. Cryptic species are found in almost all groups of organisms, and in the case of insects, their presence is a very frequent phenomenon in several orders $[4,5]$. In the field of epidemiology, the correct identification of species in insect groups with medical importance is a key component for the design of vector control and surveillance strategies [6]. This is mainly because different species may vary in terms of their competence as vectors and their epidemiological importance as well as in their susceptibility to insecticides or other control strategies [7].

One of the most epidemiologically important groups of insects on the American continent is the triatomines (Triatominae: Reduviidae), the vectors of Chagas disease (CD). In this group, the genus Triatoma is the most diverse genus [8]; approximately 70 species have been described and it is the genus with the largest geographical distribution within the subfamily $[9,10]$. Multiple interand intraspecies taxonomic questions have arisen in this group, with species repeatedly included and excluded from different complexes throughout the history of the study of their systematics and taxonomy [11-14]. The combination of unresolved taxonomic relationships and the detection of cryptic species within this genus highlight the need to address the systematics of this group [15-18]. The phenomenon of cryptic speciation is common in the Triatominae [19-21] and results in species that are nearly identical morphologically, which often makes identification based only on traditional morphological characters difficult or impossible.

The identification of triatomine species has usually been carried out using traditional morphometry [11, 14, $22,23]$. However, the use of geometric morphometry has led to new techniques for evaluating morphological characters in a taxonomic context; it complements the use of other methods of discrimination [24] and has been used for the recognition of very close species with a long history of controversy among taxonomists [25] and apparently cryptic species, including some of the genus Triatoma [7, 26-32].

The Triatoma dimidiata complex represents one of the major vectors of Chagas disease in all the countries where it is distributed [18, 33, 34]. It is present in Mexico, all the countries of Central America, Colombia, Ecuador and Perú $[18,35]$. Throughout its range, it can be found in jungle, peridomestic and domestic habitats, where non-domiciled populations act as sources of re-infestation and participate in the transmission of the parasite to humans [35-38].

Phylogenetic studies using sequences from cytb, nad4, and $16 S$ rRNA genes, have defined three lineages in Mexico and part of Central America (with 6-14\% divergence among haplogroups) $[15,39]$, which were recently reaffirmed by Pech-May et al. [18]. Using geometric morphometry techniques with a landmark-based analysis, Gurgel-Gonçalves et al. [40] reached correct identification rates of $70.5 \%, 76.7 \%$ and $82.5 \%$ for haplogroups 1 , 2 and 3 of T. dimidiata respectively. More recently, Khalighifar et al. [41] using TensorFlow [42], an open-source software platform, representing the most recent addition to the deep learning toolbox [43] (Google Brain Team; https://research.google.com/teams/brain/), were able to increase the correct classification of specimens of the three haplogroups $(84.1 \% \mathrm{H} 1,86.7 \% \mathrm{H} 2$ and $87.5 \% \mathrm{H} 3)$ [41]. Although these methodologies are the cutting-edge approach to the automatized species identification within the Triatomine group, this rate of identification is still insufficient and methods that guarantee higher power of correct discrimination are still necessary.

As an alternative, in this study we propose the use of elliptical Fourier descriptors (EFDs), which can delineate any shape with a two-dimensional closed contour, as suggested by Kuhl and Giardina [44]. Contour analysis is based on the digitalization of the silhouette of an object, which is expressed as a sequence of coordinates $(x, y)$ that can be manipulated mathematically and adjusted to an equation derived from Fourier functions. For the extraction and digitization of outline characters, the elliptic Fourier algorithm has the advantages of being able to reconstruct outlines, eliminate errors in orientation caused by interference, size images and trace the starting point of an original image [45-48]. This method has been widely applied to the analysis of various biological shapes $[48,49]$ and more recently, as a tool for pattern detection, correct insect identification and automatic identification systems [50-52]. For the Triatominae in particular, the elliptic Fourier algorithm has been used with the objective of identifying species from the analysis of different structures $[27,53]$.

Here, we apply EFDs in order to evaluate their ability to identify the three described $T$. dimidiata haplogroups for Mexico and part of Central America. The results of this evaluation contribute to the implementation of tools for accurate discrimination between triatomine species and potentially to the control and prevention of $\mathrm{CD}$. 


\section{Methods}

\section{Sample information}

In order to test the ability of EFDs to discriminate among the haplogroups of $T$. dimidiata, we used the images obtained by Gurgel-Gonçalves et al. [40], which are available in the Dryad Digital Repository (http://dx.doi. org/10.5061/dryad.br14k). The original series of photos for triatomines were taken from entomological collections across Mexico (Centro Regional de Investigación en Salud, Instituto Nacional de Salud Pública, México; Laboratorio Estatal de Salud Pública de Guanajuato; Universidad Autónoma Benito Juárez, Oaxaca; Universidad Autónoma de Nuevo León, Monterrey), and 44, 30 and 40 images of haplogroups 1, 2 and 3 were obtained, respectively, with which the automated identification process tested by Gurgel-Gonçalves et al. [40] was performed. For this study, only images that had the necessary characteristics to perform the contour analysis were selected, i.e. only images with an unmodified contour and wings that were not broken or overlapped. This filtering process resulted in a total sample of $37\left(21 \%, 160^{\star}\right)$, $23\left(17 \%, 60^{\star}\right)$ and $36\left(17 \%, 190^{\star}\right)$ images for haplogroups 1,2 and 3 , respectively. The conditions under which the photographs were taken, and more information about the samples, are detailed in Gurgel-Gonçalves et al. [40].

\section{Images manual pre-processing}

The images were manually pre-processed in Adobe Photoshop CS5. This pre-processing involved the removal of the legs and antennas from each image leaving only the body contour. The brightness and contrast values were adjusted to their minimum and maximum values, respectively, to leave only a binary image (Fig. 1). All images were saved as bitmaps (BMP) in 24-bit RGB format.

\section{Obtention of Triatoma dimidiata haplogroups body contour and measurement error}

To extract and quantify body contours of the $T$. dimidiata haplogroups we used SHAPE 1.3 software [54], designed to evaluate the contour shape based on elliptical Fourier transform. The observed contour is decomposed in terms of sine and cosine curves of successive frequencies called harmonics, and each harmonic is described by four coefficients. The closed contours of simple shapes can be expressed in polar coordinates with the radius as a function of the angle from a fixed internal point, which constitutes a periodic function. In this way, all the information about the shape in the sequence of points will be reduced to a smaller number of parameters whose distribution can be studied in the morphological space with the coefficients as axes [48]. Elliptical Fourier descriptors are an extension of this method, applicable when the contours are so complex that there could be more than one radius value per angle [55]. The method is developed by taking increments in $\mathrm{X}$ and $\mathrm{Y}$ between points, to define the periodic function [44]. A more detailed mathematical description of contour extraction based on EFDs can be found in Iwata et al. [56].

SHAPE has four subprograms (ChainCoder, Chc2Nef, PrinComp and PrinPrint) which together facilitate the processing of digital images, acquisition of the chain code and Fourier coefficients, and principal components analysis. It also includes routines for the visualization of the shape from previously digitized data (ChcViewer and NefViewer).

The chain code is a coding system to describe the spatial information of the contours with numbers from 0 to 7 [57]; digits indicate the direction of the next step around an outline: 0 , one step to the right; 2 , one step up; 4 , one to the left; 6 , one down; and the other digits are intermediate addresses. In order to obtain this code for each image, the ChainCoder subprogram was implemented for images of the haplogroups. This subprogram reads the BMP images, converts them to grayscale, binarizes them from a threshold value selected in the image histogram, eliminates possible noise existing in the images using erosion-dilution filters and obtains the chain code by edge detection and the contour information is stored as chain code, which is saved in an ASCII file with an extension chc. In all cases, digitization starts from the same homologous point from one image to another. Here, all images were converted to grayscale using the red channel, binarized with a threshold value of 150 and the erosion and dilution filters were worked with values of 1 and 10 respectively.

Once the chain code file was generated, for each image using the Chc2Nef program the Fourier transform coefficients for $5,10,15,20,25$ and 30 harmonics were calculated consecutively, to evaluate the minimum number of harmonics that allow to achieve the best discrimination between haplogroups. We used the first harmonic ellipse parameters, to normalize the elliptic Fourier (NEF) coefficients so that they are invariant to size, rotation, and the starting position of the outline trace. NEF were stored in an ASCII file of extension.nef, and the four coefficients (related to the width-on-length ratio of the outline) were used for subsequent multivariate analyses [58].

Given that many variables (NEF) are produced (four coefficients for each harmonic), a principal components analysis (PCA) was performed using the variance-covariance matrices to reduce the dimensionality and obtain new derived variables that can be analyzed statistically. This was done using the PrinComp module, as proposed by Rohlf \& Archie [48], and the scores of the first five principal components (PCs) that contributed most to the total variance were used as new shape variables. 

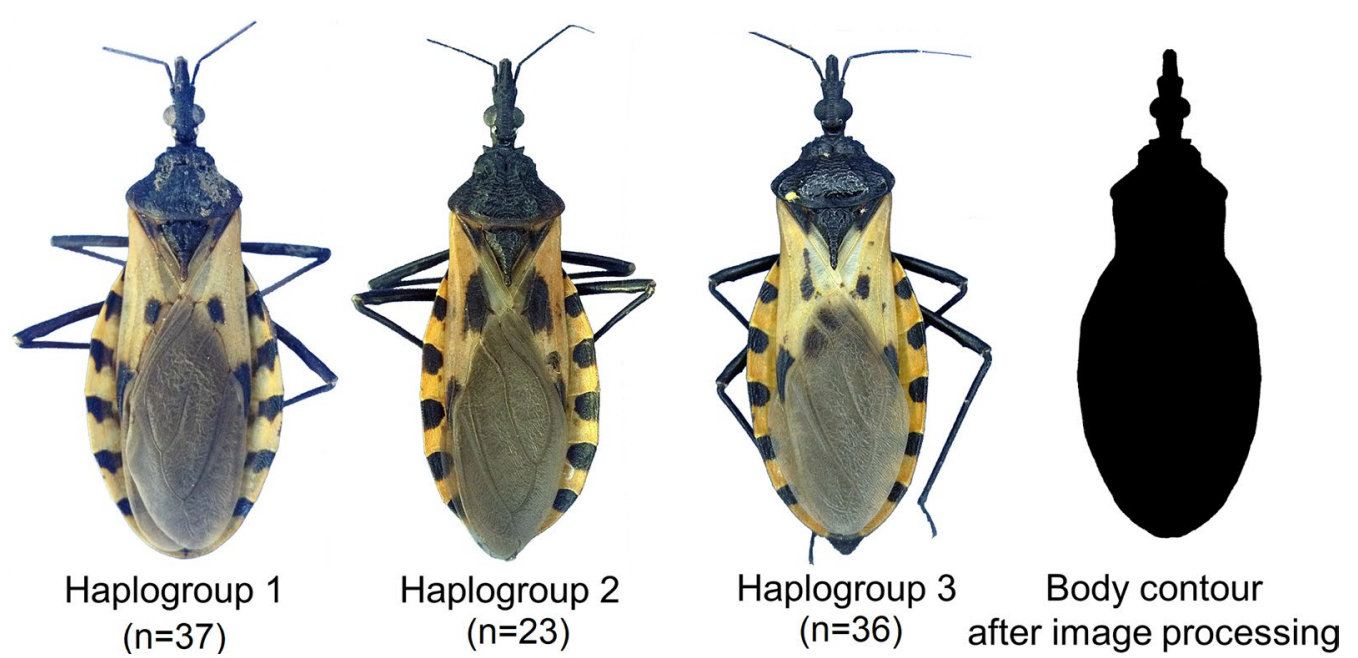

Fig. 1 Image examples of the three haplogroups of Triatoma dimidiata (Hemiptera: Reduviidae) and of a body contour after image processing for the analysis of the elliptical Fourier descriptors. Sample sizes per haplogroup are shown in parentheses under each image. Copyright: Creative Commons Attribution 1.0 Universal (CCO 1.0) Public Domain Dedication license (https://creativecommons.org/licenses/by/1.0). Images modified from Gurgel-Gonçalves R, Komp E, Campbell LP, Khalighifar A, Mellenbruch J, Mendonça VJ, et al. Automated identification of insect vectors of Chagas disease in Brazil and Mexico: the virtual vector lab. PeerJ. 2017;5:e3040 [40]

The variance contribution of all principal components is reported in Additional file 1: Table S1. The PCs contain all the information for each haplogroup body shape, as demonstrated by the fact that the contours can be graphically reconstructed from these, using an inverse Fourier transform in the PrinPrint module, according to the procedure of Furuta et al. [59]. Because in some cases, several main components can recover the contour with a high degree of precision, the first three that contributed most to the total variance were used to evaluate the interspecific and intraspecific differences in the contour. The rest of the reconstructions (the overlap between haplogroups and the individual reconstruction of each haplogroup) are shown in Additional file 2: Figure S1.

To estimate the measurement error of intraspecific variations, we produced 30 replications of 15 specimens for each haplogroups $[60,61]$. Each contour of an individual was imaged and edited 30 times. An ANOSIM analysis was used to partition the total of the 1st PCs for each haplogroup into within and between-individual variations. The percentage measurement error was determined by the method indicated in Yezerinac et al. [60].

\section{Contour shape discrimination and statistical analysis}

To evaluate the ability of FEDs to discriminate among three haplogroups of $T$. dimidiata, a discriminant function analysis was performed to determine the minimum number of harmonics needed to produce the best classifications. Here we considered as the best classification the highest percentage of correct discrimination obtained for each haplogroup. For this, the PCs recovered from the PrinComp module were used. For the first five harmonics, the number of principal components was 16 , while for $10,15,20,25$ and 30 harmonics, 30 principal components were recovered. An ordination plot of the discriminant analysis was then generated with the PC of the minimum number of harmonics that allowed the best haplogroup discrimination and the confusion matrix was obtained to estimate the classification errors.

We also compared statistically the first five principal components among the three haplogroups. This allowed us to detect if the information related to the shape of the contour contained in the PCs presented enough differences between haplogroups. Because all the data were not normally distributed, we performed a Kruskal-Wallis test to compare among the three haplogroups.

As an alternative method of discrimination and identification, a multilayer perceptron neural networks were trained. Artificial neural networks are mathematical models constructed by simulating the functioning of biological neural networks (the nervous system). They present a set of processing units called neurons, cells or nodes (formed by several mathematical equations), interconnected by connections that include a weight that modifies the values that pass through them between neurons [61]. Artificial neural networks (ANNs) have been advocated in many disciplines for addressing complex pattern-recognition problems. The advantages of ANNs over traditional, linear approaches include their ability to model non-linear associations with a variety of data 
types (e.g. continuous, discrete) and to accommodate interactions among predictor variables without any a priori specification [62]. Neural networks are considered universal approximators of continuous functions, and as such, they exhibit flexibility for modeling non-linear relationships between variables. For example, ANNs exhibit substantially greater predictive power than traditional, linear approaches when modeling non-linear data (based on empirical and simulated data) [63].

The variables used to make the network were the scores of the principal components that contributed most to the total variance, obtained from the Fourier coefficients from 25 harmonics. For the basic topology, the automated search procedure of Statistica version 8.0 software was used, with an input layer of 30 neurons, corresponding to each shape variable, and the output layer with three neurons, one for each haplogroup to identify.

In the exploratory step, the most efficient network was evaluated by testing with hidden layers of between 10 and 40 neurons. Two error functions (sum of squares and cross-entropy) and four activation functions (identity, logistics, tangent and exponential) were used. The learning rate was 0.1 , the inertia 0.66 , and the stopping rule was set when the training error was below 0.001. Network learning was represented using the behavior of the maximum, average and minimum errors. Sixty percent of the data were randomly selected for network training and the remaining $40 \%$ was used for validation. Of the 30 networks, the one with the lowest classification error of the validation data was selected as best. The classification power for the species was analyzed using the confusion matrix and the calculation of the percentages of omission and commission errors.

\section{Results}

\section{Measurement error of intraspecific variations} and statistical difference in shape

On the first PC (the one that most contributed to the total variance), the percentage measurement error reached $2.3 \%$ of the intraspecific variance for the haplogroup 1, 3.3\% for the haplogroup 2 and $3.6 \%$ for the haplogroup 3.

\section{Contour reconstruction and variance explained by PCA}

With the result of the first component, and when using the inversion of the Fourier transforms, the contour of the haplogroups of $T$. dimidiata was reconstructed and the variability among and within groups was graphically characterized (Fig. 2). The greatest variability among haplogroups was observed in the posterior lobe of the pronotum and the terminal region of the head and neck. This pattern of variation was also observed internally within haplogroups 1 and 2 . The greatest variation within haplogroup 3 specimens was in the anterior lobe and distal tubers (Fig. 2).

Regardless of the number of harmonics used to describe the contour, the first component explained about half of the contour variability (between 44-55\%) (Fig. 3). As the number of harmonics used increased, more components were required to explain $90 \%$ of the variation in shape, but in general, this value was reached with 8 principal components (Fig. 3).

\section{Discriminant analysis and neural network}

When performing the discriminant analysis to assess the number of harmonics that offers the best discriminations among haplogroups, it was observed that correct discriminations generally increased with the number of harmonics used. This pattern stopped at 30 harmonics when correct discrimination began to fail (Table 1). Haplogroup 1 was successfully differentiated 10 harmonics with $100 \%$ correct discrimination. Haplogroup 2 reached a $100 \%$ correct discrimination when the contour was described with 20 and 25 harmonics. Haplogroup 3 only reached $88.24 \%$ and $94.12 \%$ correct discrimination with the maximum number of harmonics tested. Overall, the best results were obtained when describing the contours of haplogroups using 25 harmonics.

The ordering diagram of the discriminating axes for the shape of the specimens, for the description of the contour with 25 harmonics and using 30 PCs is shown in Fig. 4. The separation of the minimum convex polygons demonstrated the possibility of discriminating the haplogroups using the PC as shape variables. Haplogroup 1 is separated perfectly from the rest, showing the greatest differentiation from haplogroups 2 and 3 along canonical axis 1. Haplogroups 2 and 3 presented greater variation along canonical axis 2. One individual from haplogroup 3 was located within the polygon of haplogroup 2, which was corroborated as an error of discrimination of the analysis in the confusion matrix (Table 2).

When comparing the first five PC scores among the three haplogroups, significant differences were found among, at least, two haplogroups for all principal components except for PC2 and PC3 (Fig. 5). The greatest differences were always found between haplogroups 1 and 3 .

All trained networks achieved $100 \%$ correct classification with training data, but the most efficient with validation data was a perceptron of 13 neurons in the hidden layer, which reached $91 \%$ correct classification. This network used a BFGS18 training algorithm and an SOS error function. The activation function of the hidden layer was 'Logistics' and for the output layer, 'Tangent'. This network confused only one individual of haplogroup 1 (out of a total of 20) which was classified as haplogroup 2 (dropping to $94 \%$ of correct classification), 
and two individuals of haplogroup 2 (of 16) were classified as haplogroup 3 (for $85 \%$ of correct classification). The eight individuals belonging to haplogroup 2 used to validate the network were correctly classified (100\%). Components 1, 5, 15 and 2 had the highest weight in the network.

\section{Discussion}

In entomological studies, much attention has been given to the use of different parts of the body to identify, name and classify insects [64]. To date, wings have been the most commonly used structures to assess species discrimination through geometric morphometry methods, mainly using anatomical reference points $[7,26]$. Here, to the best of our knowledge, we use for the first time the whole-body contour of an insect to discriminate among haplogroups. The use of EFDs has been little explored, though on several occasions it has demonstrated its ability to discriminate among even closely related species $[65,66]$. Even more, some studies with triatomines [27, 53] and other insects of medical importance [27, 67-69]

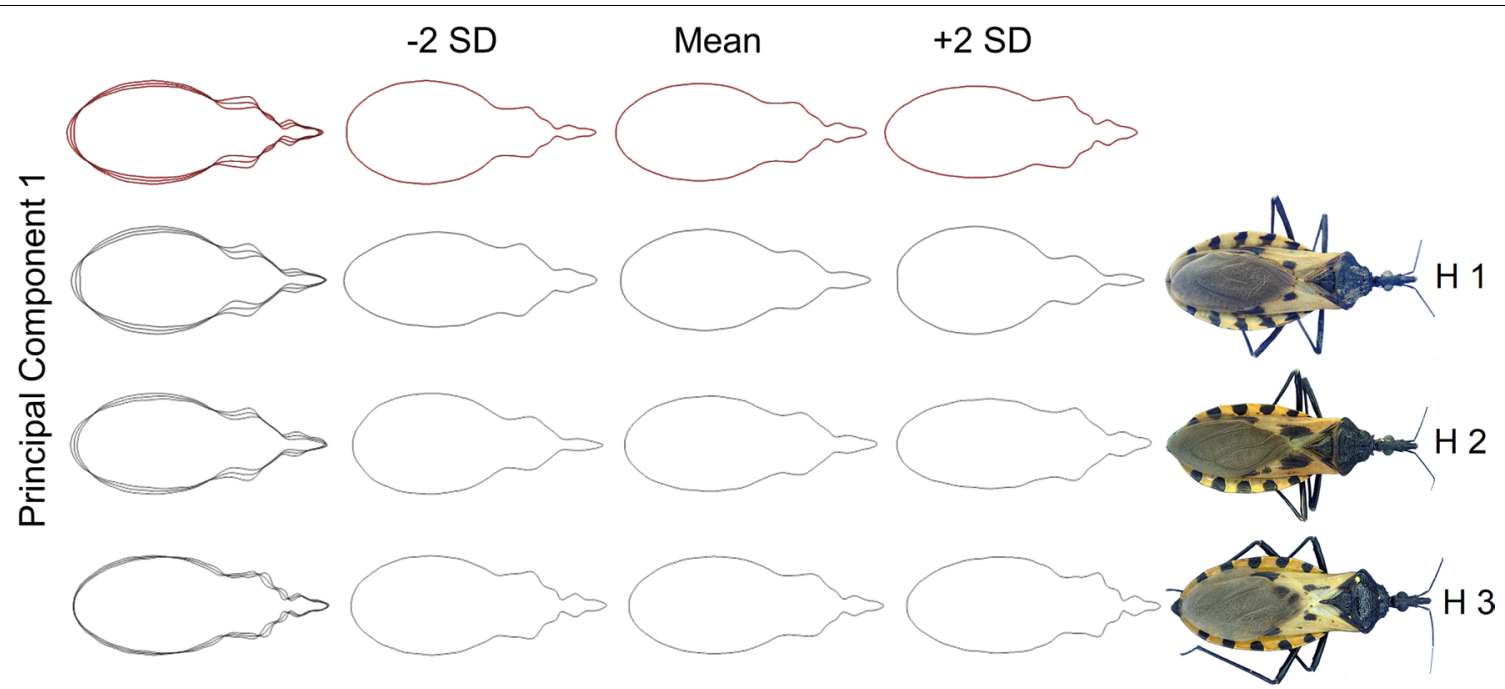

Fig. 2 Digital reconstruction and variability of the contours in three haplogroups of Triatoma dimidiata (Hemiptera: Reduviidae). The contours were obtained from the first principal components obtained with the elliptical Fourier descriptors. Red contours represent the consensus of the three haplogroups. Abbreviations: $\mathrm{H1}$, haplogroup 1; H2, haplogroup 3; H3, haplogroup 3

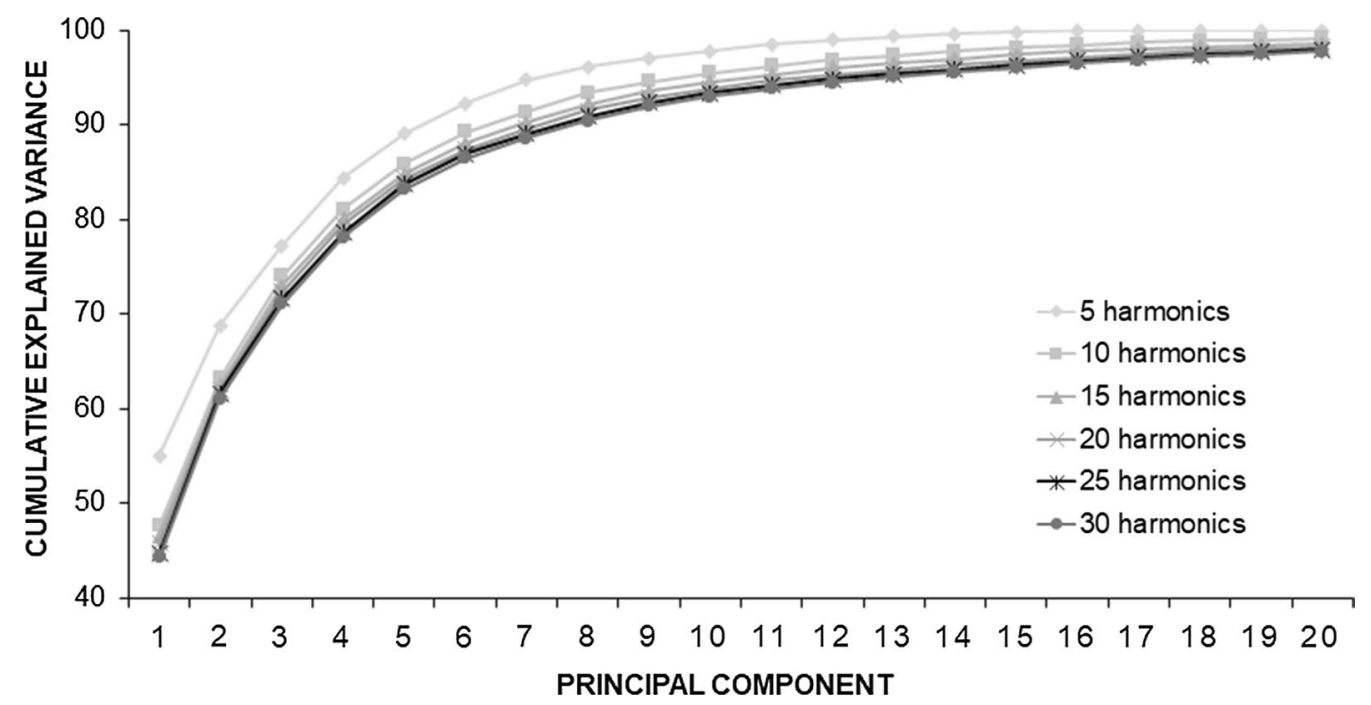

Fig. 3 Behaviour of the variance explained by the principal components as the number of harmonics used to characterize the shape of three haplogroups of Triatoma dimidiata (Hemiptera: Reduviidae) is increased 
Table 1 Percentage of correct discrimination for three haplogroups of Triatoma dimidiata (Hemiptera: Reduviidae) for discriminant analysis using 5, 10, 15, 20, 25 and 30 harmonics

\begin{tabular}{lllll}
\hline $\begin{array}{llll}\text { No. of } \\
\text { harmonics }\end{array}$ & \multicolumn{2}{l}{ Correct classification (\%) } & Total \\
\cline { 2 - 4 } & Haplogroup 1 & Haplogroup 2 & Haplogroup 3 & \\
\hline 5 & 97.14 & 60 & 88.24 & 85.39 \\
10 & 100 & 85 & 94.12 & 94.38 \\
15 & 100 & 90 & 94.12 & 95.51 \\
20 & 100 & 100 & 91.18 & 96.63 \\
$\mathbf{2 5}$ & $\mathbf{1 0 0}$ & $\mathbf{1 0 0}$ & $\mathbf{9 4 . 1 2}$ & $\mathbf{9 7 . 7 5}$ \\
30 & 100 & 95 & 94.12 & 96.63 \\
\hline
\end{tabular}

Note: The best correct discrimination values for a certain number of harmonics are highlighted in bold

have demonstrated the usefulness of these methods for species recognition in this genus.

When using the inversion of the Fourier transforms, it was possible to visualize that the greatest differences in contour shape between the haplogroups were found in the pronotum and the head. Both structures have been used in morphometric studies, both traditional and geometric, because important variations in their shape have been detected $[7,14,40]$. In the case of the head, Bustamante et al. [14] consider that an important factor in the variability observed in this region is due to the geographical isolation of the populations of T. dimidiata, which has led to divergent evolution. The haplogroups used in this study mainly have allopatric populations, which could explain the morphometric differences found, although there are areas of sympatry [18]. In turn, differences in the head may have an evolutionary cause related to feeding strategies and growth patterns of this area of the body. Some authors have suggested that the shape of the head may reflect evolutionary mechanisms related to the ability to ingest blood. If the allopatry of the haplogroups populations of $T$. dimidiata is taken into account and that these must have diverged approximately 0.97 to 0.85 mya, according to results obtained from sequences of the $n a d 4$ gene [16], dissimilar feeding strategies may have been established among the haplogroups, which

Table 2 Confusion matrix of the discrimination process of the three haplogroups of Triatoma dimidiata (Hemiptera: Reduviidae) for the ordination plot of the discriminant analysis for 25 harmonics

\begin{tabular}{lllll}
\hline Haplogroup & $\mathrm{H} 1$ & $\mathrm{H} 2$ & $\mathrm{H} 3$ & Total \\
\hline $\mathrm{H} 1$ & 37 & 0 & 0 & 37 \\
$\mathrm{H} 2$ & 0 & 23 & 0 & 23 \\
$\mathrm{H} 3$ & 0 & 1 & 35 & 36 \\
\hline
\end{tabular}

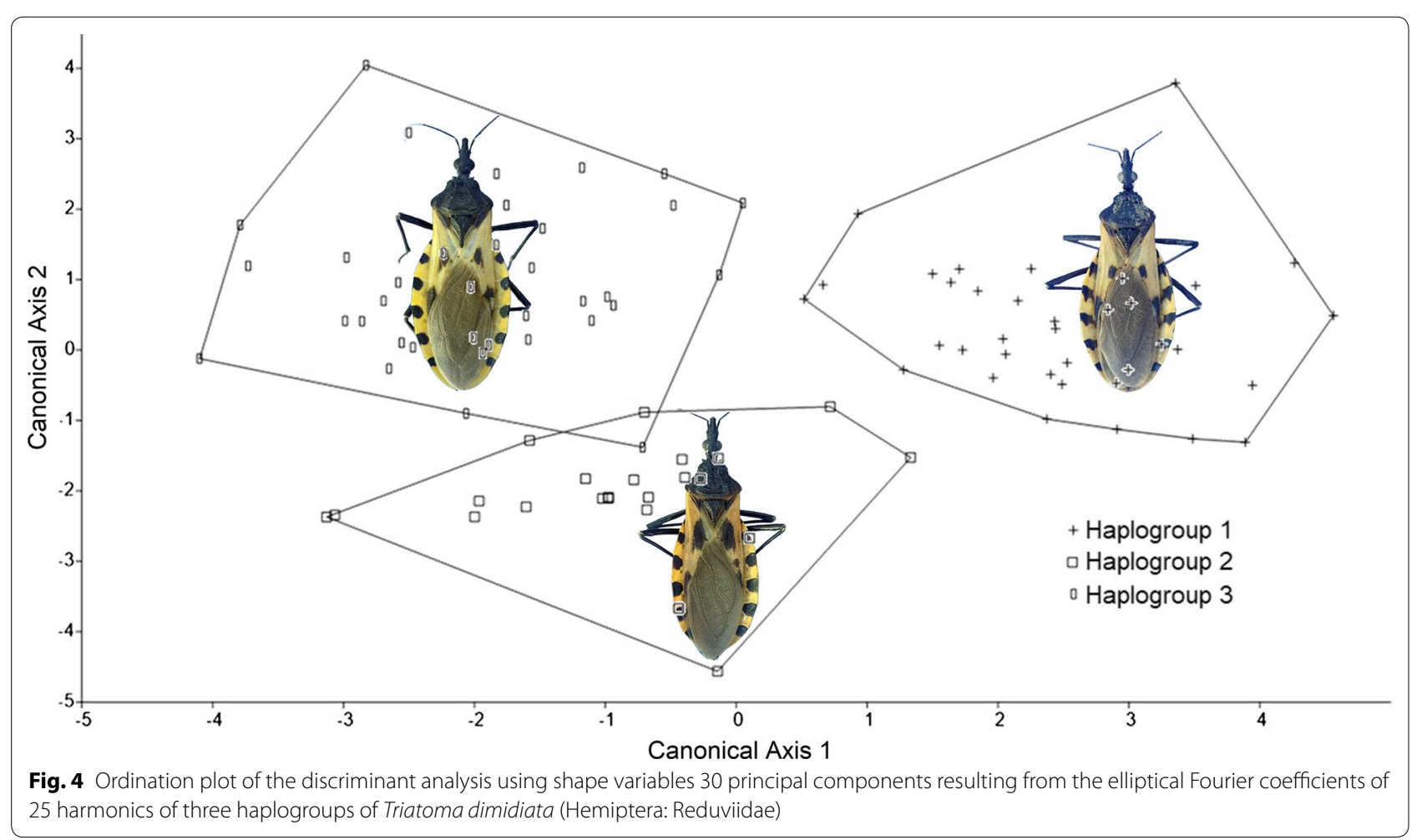




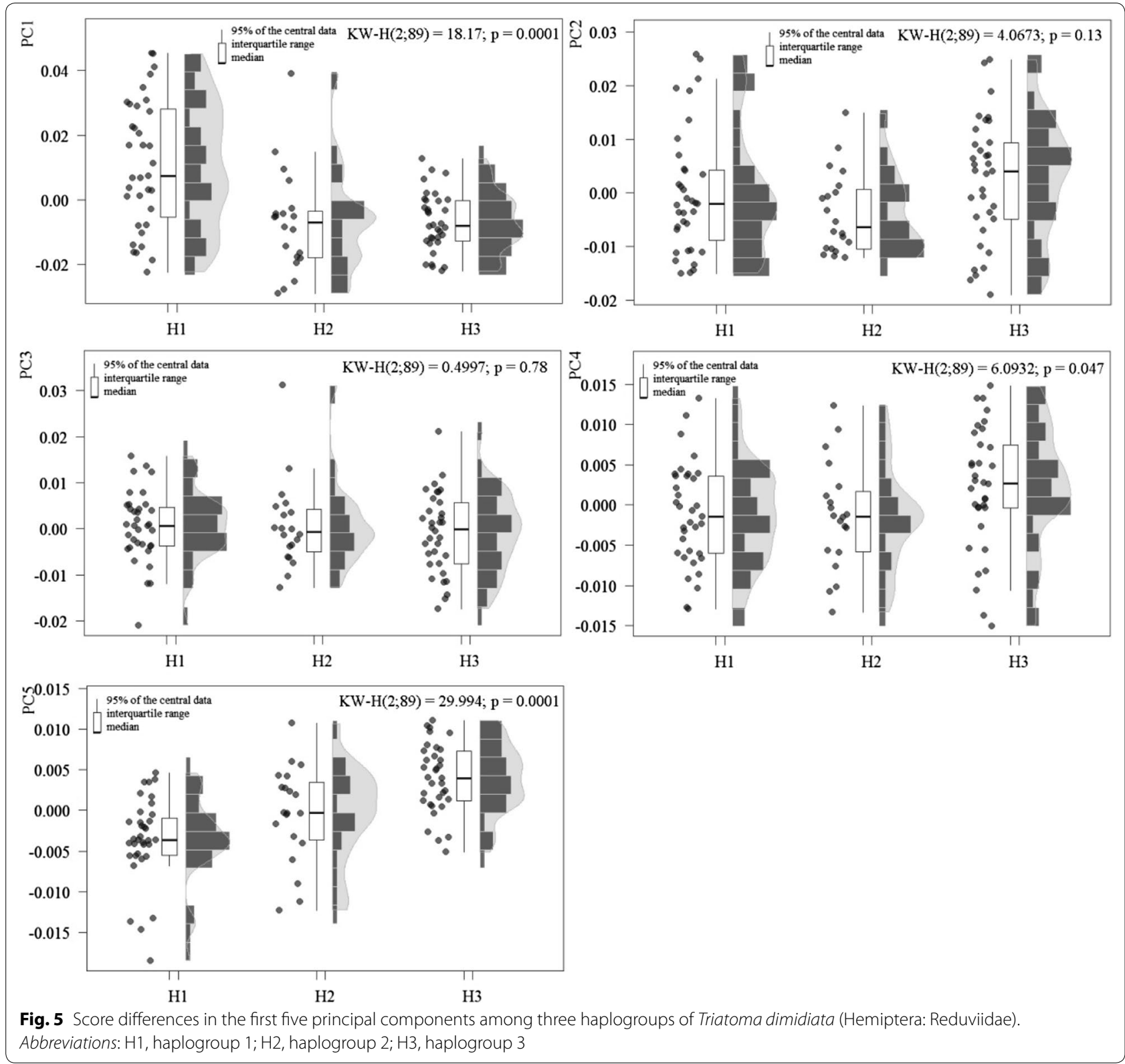

then generated morphological differences. However, because the information related to the localities where individuals where obtained is not available in the original paper [40], more precise conclusions cannot be reached.

In the case of the pronotum, significant variability in the shape of the contour between the haplogroups was also observed. This structure has been used in the traditional morphological description of triatomine species [9] and has been used in attempts to discriminate species [50]. To our knowledge, only one study has used geometric morphometry techniques on this structure in triatomines [32], in the future a comparative study of the pronotum could evaluate its utility in the discrimination among triatomines.

When comparing the results obtained by Gurgel-Gonçalves et al. [40], who reached correct discrimination values between $70.5 \%$ and $82.5 \%$ of the three haplogroups and the results obtained by Khalighifar et al. [41] (with correct discrimination values of $84.1 \% \mathrm{H} 1,86.7 \% \mathrm{H} 2$ and $87.5 \% \mathrm{H} 3$ ) our results reached $100 \%$ correct discrimination values for haplogroup 1 and 2 and 94.12\% for haplogroup 3, with total discrimination results of $97.75 \%$, 
through discriminant function analysis. This is probably because, in comparison to the methods used in the studies mentioned above, EFDs can recover a greater variability of the shape through the contour analysis. Perhaps the integration of both, the methods of the previous studies $[40,41]$ (which have demonstrated their ability with good values of correct discrimination in the recognition of these haplogroups) and EFDs, can help to establish an identification system of the haplogroups of $T$. dimidiata with higher values of correct identification.

This method of describing shapes and reconstructing images is advantageous when the analysis based on anatomical reference points fails to fully discriminate the objects of study. McLellan and Endler [70] suggested that the use of EFDs provides a precise reconstruction of the contour of the complex object and can explain the overall complexity of the shape with greater resolution than the methods of anatomical reference points and semilandmarks. This has been demonstrated in other insect groups, where the use of EFDs has allowed the correct discrimination between species [71]. Francoy et al. [24] used both methods (anatomical reference points and elliptical Fourier descriptors) for the identification of euglossine bees. These authors found better results in the differentiation of species using EFD. However, they suggest the combined use of data matrices obtained by anatomical reference points and EFDs.

Species concepts and delimitation have always been highly controversial and complicated, especially when the focal organisms are considered cryptic or hypercryptic [64]. In the Triatoma genus, the presence of cryptic species has been widely addressed. Several authors have assembled the Triatoma species into different groups and complexes based on their external characters and the genitalia of both sexes [72-74]. Currently, the most accepted group was proposed by Schofield and Galvão [74], with the subdivision of Triatoma species into groups, complexes and subcomplexes.

Triatominae species show high morphological variation, which suggests that ecological factors may be the main force driving speciation in the Triatominae [22]. Very closely related species can develop rapid morphological changes in adaptation to new environments. Conversely, similar morphs adapted to the same ecotope could be derived from different ancestors [22]. Thus, the existence of morphologically similar species could be reflecting their evolution from a common ancestor or convergent adaptation to the same ecological niche. This phenotypic flexibility leads to the misidentification of distinct genetic units by morphological convergence, resulting in taxonomic uncertainties in the description of new subspecies, species or even genera. Considering that the Triatominae species groupings into complexes and subcomplexes are mainly based on morphological similarities [75], the morphological plasticity complicates both species identification and the establishment of evolutionarily related groups. In this sense, traditional morphological analysis has failed to clarify the differences that other sources of evidence, such as genetic, chromosomal, karyotype analyses, etc., have contributed to the clarification of the cryptic species complexes.

Specifically, in T. dimidiata, wide distribution and variation in morphology (historically explained by wide clinal variation along its distribution range) [11], has resulted in a long history of reconsiderations of its taxonomic status, from a single species to a species complex of distinct taxonomic groups [76]. Studies focused on the analysis of morphological variation using classical morphometry techniques have led to the inclusion of $T$. dimidiata populations within other species complexes such as phyllosoma [14]. However, these considerations have been rejected due to genetic evidence that has demonstrated the presence of different haplogroups within the dimidiata complex; this demonstrates that it is impossible for classical morphological techniques to correctly discriminate among these haplogroups.

\section{Conclusions}

The use of elliptic Fourier descriptors allows the identification of three haplogroups of Triatoma dimidiata with higher precision than previous works, where higher values of correct discriminations were $82.5 \%$ [40] and $87.5 \%$ [41]. With 25 harmonics and 30 components, the identification of haplogroups was achieved with an overall efficiency greater than $97 \%$ by using discriminant analysis. The multilayer perceptron neural networks were also efficient in identification, reaching $91 \%$ efficiency with the validation data. The main advantage is its easy application from easily obtainable digital images with minimal and uncomplicated processing, which guarantees its replicability. Despite its relative mathematical complexity, it can be partially automated, which minimizes the researcher manipulation errors when processing the samples. Its ability to reconstruct the shape automatically, after statistical processing, is also attractive and does not require any drawing skills from the researcher, allowing the visual identification of the location of the differences detected. The assessment of the identification ability of this method in other triatomine species is a necessary aspect to advance procedures that allow the automation of the identification of these important vectors of Chagas disease. 


\section{Supplementary information}

Supplementary information accompanies this paper at https://doi. org/10.1186/s13071-020-04202-2.

Additional file 1: Table S1. Variance contribution of all principal components obtained with the PrinComp module. https://doi.org/10.6084/ m9.figshare.12014976.v1

Additional file 2: Figure S1. Digital reconstruction and variability of the contours in three haplogroups of Triatoma dimidiata (Hemiptera: Reduviidae), obtained from all principal components derived from the elliptical Fourier descriptors. https://doi.org/10.6084/m9.figshare.12014979.v1.

\section{Abbreviations}

CD: Chagas disease; EFD: Elliptic Fourier descriptors; H1: Haplogroup 1; H2: Haplogroup 2; H3: Haplogroup 3.

\section{Acknowledgments}

The authors want to thank Daily Martínez Borrego who provided comments on the manuscript. We also want to thank the anonymous reviewers and associate editors, whose review, comments, and suggestions were extremely valuable in improving this work.

\section{Authors' contributions}

DDC and EA conceived the study. DDC and DDA conducted all statistical analyses. DDCF, EA, DDA and CNIB wrote the manuscript. All authors contributed to the final draft of the manuscript. All authors read and approved the final manuscript.

\section{Funding}

DDC was supported by a CONACYT scholarship program

2018-000012-01NACF-11846.

\section{Availability of data and materials}

Data supporting the conclusions of this article are included in the article and its additional files. Raw data are available upon request to the first author. Also, all data derived from this investigation are deposited in the Figshare repository (https://doi.org/10.6084/m9.figshare.11344073.v1)

\section{Ethics approval and consent to participate}

Not applicable.

\section{Consent for publication}

Not applicable.

\section{Competing interests}

The authors declare that they have no competing interests.

\section{Author details}

${ }^{1}$ Centro de Investigación en Biodiversidad y Conservación (CIByC), UAEM, Cuernavaca, Morelos, México. ${ }^{2}$ Departamento de Biología Animal y Humana, Facultad de Biología, Universidad de La Habana, Havana, Cuba. ${ }^{3}$ Departamento de Ecología Humana, Centro de Investigación y de Estudios Avanzados del IPN (CINVESTAV), Unidad Mérida, Yucatán, México.

Received: 2 April 2020 Accepted: 20 June 2020

Published online: 01 July 2020

\section{References}

1. Rivera PC, González-Ittig R, Robainas A, Trimarchi LI, Levis S, Calderón G, Gardenal C. Molecular phylogenetics and environmental niche modeling reveal a cryptic species in the Oligoryzomys flavescens complex (Rodentia, (ricetidae). J Mamm. 2018;99:363-76.

2. Bickford D, Lohman DJ, Sodhi NS, Ng PK, Meier R, Winker K, et al. Cryptic species as a window on diversity and conservation. Trends Ecol Evol. 2007;22:148-55.
3. Struck TH, Feder JL, Bendiksby M, Birkeland S, Cerca J, Gusarov VI, et al Finding evolutionary processes hidden in cryptic species. Trends Ecol Evol. 2018:33:153-63.

4. Jackson JK, Resh VH. Morphologically cryptic species confound ecological studies of the caddifishy genus Gumaga (Trichoptera: Sericostomatidae) in northern California. Aquat Insect. 1998;20:69-84

5. Schonrogge K, Barr B, Wardlaw JC, Napper E, Gardner MG, Breen J, et al. When rare species become endangered: cryptic speciation in myrmecophilous hoverfishes. Biol J Linn Soc. 2002;75:291-300.

6. Abad-Franch F, Monteiro FA. Molecular research and the control of Chagas disease vectors. Anais Acad Bras Ciências. 2005;77:437-54.

7. Gurgel-Gonçalves R, Ferreira JBC, Rosa AF, Bar ME, Galvao C. Geometric morphometrics and ecological niche modelling for delimitation of nearsibling triatomine species. Med Vet Entomol. 2011;25:84-93.

8. Martínez FH, Villalobos GC, Cevallos AM, De la Torre P, Laclette JP, Alejandre-Aguilar R, Espinoza B. Taxonomic study of the Phyllosoma complex and other triatomines (Insecta: Hemiptera: Reduviidae) species of epidemiological importance in the transmission of Chagas disease using ITS-2 and mtCytB sequences. Mol Phylogenet Evol. 2006;41:279-87.

9. Panzera F, Hornos S, Pereira J, Cestau R, Canale D, Diotaiutu L, Dujardin JP, Pérez R. Genetic variability and geographic differentiation among three species of triatomine bugs (Hemiptera: Reduviidae). Am J Trop Med Hyg. 1997;57:732-9.

10. Ramsey JM, Peterson AT, Carmona-Castro O, Moo-Llanes DA, Nakazawa Y, Butrick M, et al. Atlas of Mexican Triatominae (Reduviidae: Hemiptera) and vector transmission of Chagas disease. Mem Inst Oswaldo Cruz. 2015:110:339-52

11. Lent $H$, Wygodzinsky P. Revision of Triatominae (Hemiptera: Reduviidae) and their significance as vector of Chagas' disease. Bull Am Museum Nat His. 1979;163:123-520.

12. Schofield CJ. Triatominae: biology and control. Bognor Regis: Eurommunica Publications; 1994. p. 80.

13. Flores A, Magallón-Gastélum E, Bosseno MF, Ordoñez R, Kasten FL, Espinoza B, et al. Isoenzyme variability of five principal triatomine vector species of Chagas disease in Mexico. Infect Genet Evol. 2001;1:21-8.

14. Bustamante DM, Monroy C, Menes M, Rodas A, Salazar-Schettino PM, Rojas $\mathrm{G}$, et al. Metric variation among geographic populations of the Chagas vector Triatoma dimidiata (Hemiptera: Reduviidae: Triatominae) and related species. J Med Entomol. 2004;41:296-301.

15. Bargues MD, Klisiowicz DR, Gonzalez-Candelas F, Ramsey JM, Monroy C, Ponce C, Salazar-Schettino PM, et al. Phylogeography and genetic variation of Triatoma dimidiata, the main Chagas disease vector in Central America, and its position within the genus Triatoma. PLoS Negl Trop Dis. 2008;2:e233.

16. Ibarra-Cerdeña CN, Zaldívar-Riverón A, Peterson AT, Sánchez-Cordero V, Ramsey JM. Phylogeny and niche conservatism in North and Central American triatomine bugs (Hemiptera: Reduviidae: Triatominae), vectors of Chagas' disease. PLoS Negl Trop Dis. 2014;8:e3266.

17. Justi SA, Russo CA, Mallet JR, Obara MT, Galvao C. Molecular phylogeny of Triatomini (Hemiptera: Reduviidae: Triatominae). Parasit Vectors. 2014;7:149.

18. Pech-May A, Mazariegos-Hidalgo CJ, Izeta-Alberdi A, López-Cancino SA, Tun-Ku E, De la Cruz-Félix K, et al. Genetic variation and phylogeography of the Triatoma dimidiata complex evidence a potential center of origin and recent divergence of haplogroups having differential Trypanosoma cruzi and DTU infections. PLoS Negl Trop Dis. 2019;13:e0007044.

19. Monteiro FA, Barrett TV, Fitzpatrick S, Cordon-Rosales C, Feliciangeli D, Beard CB. Molecular phylogeography of the Amazonian Chagas disease vectors Rhodnius prolixus and R. robustus. Mol Ecol. 2003;12:997-1006.

20. Gardim S, Almeida CE, Takiya DM, Oliveira J, Araújo RF, Cicarelli RM, da Rosa JA. Multiple mitochondrial genes of some sylvatic Brazilian Triatoma: non-monophyly of the T. brasiliensis subcomplex and the need for a generic revision in the Triatomini. Infect Genet Evol. 2014;23:74-9.

21. Jurberg J, Cunha V, Cailleaux S, Raigorodschi R, Lima MS, Rocha DDS, Moreira F. Triatoma pintodiasi sp nov do subcomplexo Trubrovaria (Hemiptera, Reduviidae, Triatominae). Rev Pan-Amaz Saude. 2013:4:43-56.

22. Dujardin JP, Panzera P, Schofield CJ. Triatominae as a model of morphological plasticity under ecological pressure. Mem Inst Oswaldo Cruz. 1999;94(Suppl. 1):223-8.

23. Carcavallo RU, Martínez A. Comunicaciones científicas: entomoepidemiología de la República Argentina. La Plata: Junta de Investigaciones 
Científicas de las Fuerzas Armadas Argentinas. 1968. http://www.world cat.org/oclc/7247216.

24. Francoy TM, Silva RAO, Nunes-Silva P, Menezes C, Imperatriz-Fonseca VL. Gender identification of five genera of stingless bees (Apidae, Meliponini) based on wing morphology. Genet Mol Res. 2009;8:207-14.

25. Bargues MD, Schofield C, Dujardin JP. The phylogeny and classification of the triatominae. In: Telleria J, Tibayrenc M, editors. American trypanosomiasis: Chagas disease, one hundred years of research. Amsterdam: Elsevier; 2010.

26. Nouvellet P, Ramirez-Sierra MJ, Dumonteil E, Gourbiere S. Effects of genetic factor and infection status on wing morphology of Triatoma dimidiata species complex in the Yucatan peninsula, Mexico. Infect Genet Evol. 2011;11:1243-9.

27. Dujardin JP, Kaba D, Solano P, Dupraz M, McCoy KD, Jaramillo-O N Outline-based morphometrics, an overlooked method in arthropod studies? Infect Genet Evol. 2014;28:704-14.

28. Gurgel-Gonçalves R, Abad-Franch F, Ferreira JB, Santana DB, Cuba CAC. Is Rhodnius prolixus (Triatominae) invading houses in central Brazil? Acta Trop. 2008;107:90-8.

29. Vendrami DP, Obara MT, Gurgel-Gonçalves R, Ceretti-Junior W, Marrelli MT. Wing geometry of Triatoma sordida (Hemiptera: Reduviidae) populations from Brazil. Infect Genet Evol. 2017:49:17-20.

30. Dujardin JP, Beard CB, Ryckman R. The relevance of wing geometry in entomological surveillance of Triatominae, vectors of Chagas disease. Infect Genet Evol. 2007;7:161-7.

31. Oliveira J, Marcet PL, Takiya DM, Mendonça VJ, Belintani T, Bargues MD, et al. Combined phylogenetic and morphometric information to delimit and unify the Triatoma brasiliensis species complex and the Brasiliensis subcomplex. Acta Trop. 2017;170:140-8.

32. Nattero J, Piccinali RV, Lopes CM, Hernández ML, Abrahan L, Lobbia PA, Rodríguez CS, de la Fuente ALC. Morphometric variability among the species of the Sordida subcomplex (Hemiptera: Reduviidae: Triatominae): evidence for differentiation across the distribution range of Triatoma sordida. Parasit Vectors. 2017;10:412.

33. Dujardin JP, Schofield J, Panzera F, Matias A, De La Riva J. Los vectores de la enfermedad de Chagas. Bruxelles: Académie Royale des Sciences d'Outre-Mer. 2002;25:189. (Mémoire in-8 $8^{\circ}$.Nouvelle Série; 3).ISBN 90-75652-27-5.

34. Galvão C, Carcavallo R, Da Silva Rocha D, Jurberg J. A check-list of the current valid species of the subfamily Triatominae Jeannel, 1919 (Hemiptera, Reduviidae) and their geographical distribution with nomenclatural and taxonomic note. Zootaxa. 2003:202:1-36

35. Zeledón, R. El Triatoma dimidiata (Latreille, 1811): y su relación con la enfermedad de chagas (No. 595.754 Z49t). San José, CR: EUNED; 1981

36. Acevedo F, Godoy E, Schofield CJ. Comparison of intervention strategies for control of Triatoma dimidiata in Nicaragua. Mem Inst Oswaldo Cruz. 2000;95:867-71.

37. Monroy MC, Bustamante DM, Rodas AG, Enriquez ME, Rosales RG. Habitats, dispersion and invasion of sylvatic Triatoma dimidiata (Hemiptera: Reduviidae: Triatominae) in Peten, Guatemala. J Med Entomol. 2003;40:800-6.

38. Nakagawa J, Juárez J, Nakatsuji K, et al. Geographical characterization of the triatomine infestations in north-central Guatemala. Ann Trop Med Parasitol. 2005;99:307-15.

39. Harris K. Taxonomy and phylogeny of North American Triatominae: public health implications. Atlanta: Moorehouse School of Medicine; 2003.

40. Gurgel-Gonçalves R, Komp E, Campbell LP, Khalighifar A, Mellenbruch J, Mendonça $\mathrm{VJ}$, et al. Automated identification of insect vectors of Chagas disease in Brazil and Mexico: the virtual vector lab. PeerJ. 2017;5:e3040.

41. Khalighifar A, Komp E, Ramsey JM, Gurgel-Gonçalves R, Peterson AT. Deep learning algorithms improve automated identification of Chagas disease vectors. J Med Entomol. 2019:56:1404-10.

42. Abadi M, Barham P, Chen J, Chen Z, Davis A, Dean J, et al. Tensorflow: a system for large-scale machine learning. In: 12th Symposium on Operating Systems Design and Implementation (ODSI 16), 2-4 November 2016, Savannah, USA: 2016. p. 265-83.

43. Rampasek L, Goldenberg A. Tensorflow: biology's gateway to deep learning? Cell Syst. 2016;2:12-4.

44. Kuhl FP, Giardina CR. Elliptic Fourier features of a closed contour. Comput Gr Image Process. 1982;18:236-58.
45. Iwata H, Nesumi H, Ninomiya S, Takano Y, Ukai Y. Diallel analysis of leaf shape variations of citrus varieties based on elliptic Fourier descriptors. Breed Sci. 2002:52:89-94.

46. Iwata H, Niikura S, Matsuura S, Takano Y, Ukai Y. Evaluation of variation of root shape of Japanese radish (Raphanus sativus L.) based on image analysis using elliptic Fourier descriptors. Euphytica. 1998;102:143-9.

47. Kincaid DT, Schneider RB. Quantification of leaf shape with a microcomputer and Fourier transformation. Can J Bot. 1983;61:2333-42.

48. Rohlf FJ, Archie JW. A comparison of Fourier methods for the description of wing shape in mosquitoes (Diptera: Culicidae). Syst Zool. 1984;33:302-17.

49. Sheets HD, Covino KM, Panasiewicz JM, Morris SR. Comparison of geometric morphometric outline methods in the discrimination of agerelated differences in feather shape. Front Zool. 2006;3:15.

50. Singh K, Gupta I, Gupta S. Classification of bamboo species by Fourier and Legendre moment. Int J Eng Sci Technol. 2013;50:61-70.

51. Zhan QB, Wang XL. Elliptic Fourier analysis of the wing outline shape of five species of antlion (Neuroptera: Myrmeleontidae: Myrmeleontini). Zool Stud. 2012;51:399-405

52. Yang HP, Ma CS, Wen H, Zhan QB, Wang XL. A tool for developing an automatic insect identification system based on wing outlines. Sci Rep. 2015:5:12786

53. Santillán-Guayasamín S, Villacís AG, Grijalva MJ, Dujardin JP. The modern morphometric approach to identify eggs of Triatominae. Parasit Vectors. 2017:10:55.

54. Iwata H, Ukai Y. SHAPE: A computer program package for quantitative evaluation of biological shapes based on elliptic Fourier descriptors. J Hered. 2002;93:384-5

55. Ferson S, Rohlf FJ, Koehn RK. Measuring shape variation of two-dimensional outlines. Syst Zool. 1985;34:59-68.

56. Iwata H, Ebana K, Uga Y, Hayashi T. Genomic prediction of biological shape: elliptic Fourier analysis and kernel partial least squares (PLS) regression applied to grain shape prediction in rice (Oryza sativa L.). PLoS ONE. 2015;10:e0120610.

57. Freeman H. Computer processing of line-drawing images. Comp Surv. 1974:6:57-97.

58. Santillán-Guayasamín S, Villacís AG, Grijalva MJ, Dujardin JP. Triatominae: does the shape change of non-viable eggs compromise species recognition. Parasit Vectors. 2018;11:543.

59. Furuta N, Ninomiya S, Takahashi N, Ohmori H, Yasuo U. Quantitative evaluation of soybean (Glycine max L. Merr.) leaflet shape by principal component scores based on elliptic Fourier descriptor. Jpn J Bot. 1995:45:315-20.

60. Yezerinac SM, Loogheed SC, Handford P. Measurement error and morphometric studies: statistical power and observer experience. Syst Biol. 1992:41:471-82.

61. Samarasinghe S. Neural networks for applied sciences and engineering: from fundamentals to complex pattern recognition. Boca Raton: Auerbach Publications; 2016.

62. Bishop CM. Neural networks for pattern recognition. Oxford: Oxford University Press; 1995.

63. Olden JD, Jackson DA. Illuminating the "black box": a randomization approach for understanding variable contributions in artificial neural networks. Ecol Model. 2002;154:135-50.

64. Tatsuta H, Takahashi KH, Sakamaki Y. Geometric morphometrics in entomology: basics and applications. Entomol Sci. 2018;21:164-84.

65. Arribas $P$, Andújar $C$, Sánchez-Fernández D, Abellán P, Millán A. Integrative taxonomy and conservation of cryptic beetles in the Mediterranean region (Hydrophilidae). Zool Scr. 2013;42:182-200.

66. Polášek M, Godunko RJ, Rutschmann S, Svitok M, Novikmec M, Zahrádková S. Integrative taxonomy of genus Electrogena (Ephemeroptera: Heptageniidae): the role of innovative morphological analyses for species delimitation. Arthropod Syst Phylo. 2018;76:449-62.

67. Changbunjong T, Sumruayphol S, Weluwanarak T, Ruangsittichai J, Dujardin JP. Landmark and outline-based geometric morphometrics analysis of three Stomoxys flies (Diptera: Muscidae). Folia Parasitol. 2016;63:37.

68. Chaiphongpachara T, Tubsamut P. Geometric morphometry of pupae to identify four medically important flies (Order: Diptera) in Thailand. Biodiversitas. 2019:20:1504-9. 
69. Dos Santos CMD, Jurberg J, Galvão C, Martínez M. Morfometria comparada de Triatoma infestans, T.rubrovaria e T. platensis (Hemiptera, Reduviidae, Triatominae) do Uruguai, Iheringia. Sér Zool. 2009;99:56-60.

70. McLellan T, Endler JA. The relative success of some methods for measuring and describing the shape of complex objects. Syst Biol. 1998;47:264-81.

71. Chávez B, Cruz DD. Valor taxonómico de la forma del ala en seis especies de esfíngidos (Lepidoptera: Sphingidae). Revista Cubana de Ciencias Biológicas. 2015:4:98-103.

72. Usinger RL, Wygodzinsky P, Ryckman RE. The biosystematics of Triatominae. Annu Rev Entomol. 1966;11:309-30.

73. Carcavallo RU, Jurberg J, Lent H, Noireau F, Galvão C. Phylogeny of the Triatominae (Hemiptera Reduviidae). Proposals for taxonomic arrangements. Entomol Vectores. 2000;7:1-99.
74. Schofield CJ, Galvão C. Classification, evolution and species groups within the Triatominae. Acta Trop. 2009;110:88-100.

75. Pita S, Lorite P, Nattero J, Galvão C, Alevi KC, Teves SC, et al. New arrangements on several species subcomplexes of Triatoma genus based on the chromosomal position of ribosomal genes (Hemiptera-Triatominae). Infect Genet Evol. 2016;43:225-31.

76. Dorn PL, Monroy C, Curtis A. Triatoma dimidiata (Latreille, 1811): a review of its diversity across its geographic range and the relationship among populations. Infect Genet Evol. 2007;7:343-52.

\section{Publisher's Note}

Springer Nature remains neutral with regard to jurisdictional claims in published maps and institutional affiliations.
Ready to submit your research? Choose BMC and benefit from:

- fast, convenient online submission

- thorough peer review by experienced researchers in your field

- rapid publication on acceptance

- support for research data, including large and complex data types

- gold Open Access which fosters wider collaboration and increased citations

- maximum visibility for your research: over $100 \mathrm{M}$ website views per year

At BMC, research is always in progress.

Learn more biomedcentral.com/submissions 